\title{
Comparison of oil and fat supplementation on lactation performance of Nili Ravi buffaloes
}

\author{
Hifzulrahman, ${ }^{1}$ M. Abdullah, ${ }^{1}$ M. U. Akhtar, ${ }^{2}$ T. N. Pasha, ${ }^{2}$ J. A. Bhatti, ${ }^{1}$ Z. Ali, ${ }^{3}$ M. Saadullah, ${ }^{1}$ \\ and M. N. Haque ${ }^{2 *}$ \\ ${ }^{1}$ Department of Livestock Production, University of Veterinary \& Animal Sciences, Outfall Road, Lahore 54000, Pakistan \\ ${ }^{2}$ Department of Animal Nutrition, University of Veterinary \& Animal Sciences, Outfall Road, Lahore 54000, Pakistan \\ ${ }^{3}$ Applied Chemistry Research Center, Pakistan Council of Scientific and Industrial Research Laboratories Complex, Lahore 54600, Pakistan
}

\section{ABSTRACT}

The effects of feeding rumen-inert fat sources on production responses of lactating dairy cows have been well reported but less thoroughly described in lactating dairy buffalo. The objective of this study was to investigate the effect of oil and 2 different rumen-inert fat sources on dry matter intake, milk yield, milk composition, and milk fatty acid (FA) profile in Nili Ravi buffalo. Twelve multiparous mid-lactating Nili Ravi buffaloes received 4 treatments in a $4 \times 4$ Latin square design with a period length of $21 \mathrm{~d}$. The treatments were (1) the basal diet without supplementation of oil or fats (CTRL), (2) the basal diet supplemented with canola oil (CO), (3) the basal diet supplemented with calcium salts of palm FA (Ca-FA), and (4) the basal diet supplemented with high palmitic acid (PA). Dry matter intake was decreased by $4.4 \%$ in the CO compared with Ca-FA and PA. Milk yield and milk fat yield were increased by 7.8 and $14.3 \%$, respectively, in CO, Ca-FA, and PA compared with the CTRL. Milk fat content increased by $7.5 \%$, whereas milk fat yield tended to increase with the supplementation of Ca-FA and PA compared with $\mathrm{CO}$. No effect on milk yield and milk composition was observed in Ca-FA versus PA treatments. The yield of medium-chain FA was increased by $\mathrm{Ca}-\mathrm{FA}$ and $\mathrm{PA}$ versus $\mathrm{CO}$. The $\mathrm{CO}$ treatment increased the yield of long-chain FA compared with Ca-FA and PA treatments. Plasma glucose level was higher in $\mathrm{CO}, \mathrm{Ca}-\mathrm{FA}$, and $\mathrm{PA}$ compared with the CTRL. In conclusion, feeding rumen-inert fats in the lactating buffalo diet proved to be a useful strategy to increase the $3.5 \%$ fat-corrected milk yield due to the higher milk fat content in this study.

Key words: canola oil, rumen-inert fat, milk yield, buffalo

Received July 27, 2018.

Accepted December 20, 2018.

*Corresponding author: muhammad.naveed@uvas.edu.pk

\section{INTRODUCTION}

Buffalo (Bubalus bubalis) is the second largest source of milk in the world, contributing $14.4 \%$ of total milk produced per annum (FAOSTAT, 2016). India, Pakistan, and China contribute 68,22 , and $6 \%$, respectively, of the total milk produced by buffalo in the world (FAOSTAT, 2016). Buffalo milk contains higher fat content (7.8 $\pm 2.3 \%$; Pegolo et al., 2017) compared with cow milk (3.4 $\pm 0.38 \%$; Conte et al., 2016); however, the fatty acid (FA) composition of buffalo milk is similar to cow milk, as it contains 70.5 versus $69.6 \%$ SFA, 26.0 versus $24.5 \%$ MUFA, and 3.5 versus $3.8 \%$ PUFA, respectively (Pegolo et al., 2017). The concentrations of short-chain FA (SCFA), medium-chain FA (MCFA), and long-chain FA (LCFA) were also reported similar in buffalo $(9.7,53.7$, and $32.7 \%$, respectively) compared with cow milk (10.2, 47.6, and $38.0 \%$, respectively). This similar composition of FA in buffalo and cow milk provides an opportunity to explore the benefits of feeding fats used in dairy cow diets to modify milk fat yield and concentration in buffalo milk. Vegetable oils in the diet of dairy cows may alter the milk fat composition, as vegetable oils increased UFA and decreased SFA (Tanaka, 2005). Canola oil is reported to contain the highest content of UFA (approximately 90\%), mainly oleic (C18:1), linoleic (C18:2), and linolenic acids (C18:3), compared with other vegetable sources (Welter et al., 2016). However, higher concentrations of UFA in the diets of dairy cows have been reported to impede DMI and rumen function (Jenkins and Jenny, 1989; Pantoja et al., 1996). Consequently, much work has been focused on methods to include additional fat in the diet without altering rumen fermentation (review by Jenkins and McGuire, 2006). Feeding rumen-inert fat in the form of calcium soap of FA (rumen-protected UFA) or prilled saturated fats is a common practice, and they were reported to have fewer negative effects on ruminal fermentation compared with oil (Palmquist and Jenkins, 1980; Jenkins and Jenny, 1992; Rabiee et al., 2012). The use of these products has been shown 
to improve milk production, milk fat yield, and milk composition in various studies conducted on dairy cow (Mosley et al., 2007; Wang et al., 2010; Lock et al., 2013; de Souza et al., 2017).

To our knowledge, limited studies have been conducted to investigate the effect of feeding calcium soap of FA in lactating buffaloes; however, in those studies an increase in milk yield and modification in milk FA profile was observed (Polidori et al., 1997; Shelke et al., 2012). On the other hand, no study has investigated the effect of feeding prilled fats to lactating buffalo. Interestingly, previous research indicates that the protection of calcium salt from ruminal biohydrogenation is incomplete, as calcium ions partially dissociate in the rumen (Wu et al., 1991; Chouinard et al., 1997; Giesy et al., 2002). Therefore, the objective of the current study was to investigate the effect of dietary FA sources with different FA profile (oil, Ca salts of palm FA, and high palmitic acid) on DMI, milk yield, milk components, and milk FA profile in Nili Ravi buffaloes.

\section{MATERIALS AND METHODS}

\section{Animals}

The experiment was conducted from June to August 2015 in a tiestall barn located at the Dairy Animals Training and Research Center, University of Veterinary \& Animal Sciences, Ravi Campus $\left(31.02^{\circ} \mathrm{N}, 73.85^{\circ} \mathrm{E}\right.$, and $186 \mathrm{~m}$ altitude; Pattoki, Pakistan). The entire experiment was conducted in accordance with the regulations approved by the ethical committee for animal welfare at University of Veterinary \& Animal Sciences. Twelve lactating multiparous Nili Ravi buffaloes, with (mean $\pm \mathrm{SD}$ ) $7.04 \pm 0.98 \mathrm{~kg} / \mathrm{d}$ of milk yield, $6.05 \pm$ $0.56 \%$ milk fat, $452 \pm 32 \mathrm{~kg}$ of $\mathrm{BW}$, and $101 \pm 42$ DIM were used. The buffaloes were individually tied in a naturally ventilated barn and had free access to automatic drinking bowls.

\section{Experimental Design, Treatments, and Feeding}

Buffaloes were randomly assigned to a treatment sequence in a $4 \times 4$ Latin square design with 21 -d periods. The treatments were (1) the basal diet without supplementation of oil or fats (CTRL), (2) the basal diet with canola oil supplementation (CO), (3) the basal diet with calcium salts of palm FA (Ca-FA; Energizer Gold, IFFCO, Johor, Malaysia), and (4) basal diet with high palmitic acid supplementation (PA; Energizer RP-10, IFFCO). The diets were formulated using Cornell-Penn-Miner-Dairy 3.0.10 from Cornell University (Ithaca, NY), University of Pennsylvania (Philadelphia, PA), and Miner Institute (Chazy, NY), based on Cornell Net Carbohydrate and Protein System 5.0.2 (Fox et al., 2003). The diet was composed (on DM basis) of $47.7 \%$ oat silage, $19.6 \%$ wheat bran, $13.5 \%$ wheat straw, $9.97 \%$ canola meal, $5.84 \%$ ground corn, and $3.29 \%$ sugarcane molasses. Chemical composition of the basal diet is presented in Table 1. The forage-toconcentrate ratio was 60:40 as typically fed in commercial buffalo dairy farms located in periurban areas of Pakistan. Feeding rate of CO and PA was $170 \mathrm{~g} / \mathrm{d}$ and Ca-FA was $200 \mathrm{~g} / \mathrm{d}$ in the study and was adjusted to provide similar $\mathrm{NE}_{\mathrm{L}}$ in these 3 treatments. The FA profiles of oil and rumen-inert fats are presented in Table 2. The diets were offered in fixed amounts per buffalo. This was achieved by feeding an ad libitum diet $7 \mathrm{~d}$ before the start of experiment and estimating the DMI of individual buffalo. Buffaloes were relatively similar in BW; hence, they were offered a similar quantity of DM (17 kg/buffalo per day) assuming similar lactation persistency in the entire experiment. The buffaloes were fed once daily at $0900 \mathrm{~h}$.

\section{Experimental Measures, Sample Collection, and Analyses}

Diet offered as well as individual orts were weighed daily. Three samples of each feedstuff were collected weekly in each period to evaluate the DM and for further laboratory analysis. These samples were analyzed for DM, CP, NDF, ADF, ether extract, and ash following official methods of AOAC International (2005). Buffaloes were milked twice daily at 0600 and $1800 \mathrm{~h}$. Milk production was recorded at each milking. Milk samples were taken on alternate days in the first $2 \mathrm{wk}$ and consecutively on d 15 to 21 of each period. Milk production from morning and evening milking were pooled daily and assayed by infrared analysis using Lactostar 3510 (Funke-Gerber, Berlin, Germany) for fat, protein, and lactose. An aliquot of milk from d 21 of each period was stored at $-20^{\circ} \mathrm{C}$ without preservative until analyzed for FA profile. Blood samples of all the buffaloes were collected on third last day of each period from jugular vein following Haque et al. (2012). Blood samples were collected in heparinized syringes and immediately centrifuged at $2,000 \times g$ for $15 \mathrm{~min}$ at $4^{\circ} \mathrm{C}$. Plasma was separated, aliquoted, and stored at $-20^{\circ} \mathrm{C}$ to be assayed by enzymatic method and estimated for the analysis of plasma urea nitrogen (PUN; Fluitest Urea, Analyticon Biotechnologies AG, Lichtenfels, Germany), triglycerides (Fluitest TG, Analyticon Biotechnologies AG, Lichtenfels, Germany), and glucose (BioMed-Glucose L.S, Egy-Chem for lab technology, Badar city, Elrubaki, Egypt). Buffaloes were weighed on d 15 of each treatment before feed distribution. 
Table 1. Nutrient composition of the treatment ${ }^{1} \operatorname{diets}^{2}$

\begin{tabular}{lcccc}
\hline Item & CTRL & CO & Ca-FA & PA \\
\hline Ingredient (\% of DM, unless noted) & & & & \\
DM (\%) & 48.5 & 48.7 & 48.8 & 48.7 \\
Forage & 61.3 & 60.6 & 60.5 & 60.6 \\
CP & 11.8 & 11.7 & 11.7 & 11.7 \\
ADF & 30.8 & 30.4 & 30.4 & 30.4 \\
NDF & 51.3 & 50.7 & 50.6 & 50.7 \\
NFC & 27.9 & 27.6 & 27.6 & 27.7 \\
Ether extract total & 3.27 & 4.34 & 4.23 & 4.23 \\
Ash & 7.71 & 7.63 & 7.81 & 7.79 \\
Predicted nutritive values & 29.2 & 28.9 & 29.3 & 29.2 \\
RUP (\% CP) & 2.13 & 2.21 & 2.20 & 2.20 \\
ME (Mcal/kg) & 1.37 & 1.42 & 1.42 & 1.42 \\
NE (Mcal/kg) & & & \\
\hline
\end{tabular}

${ }^{1}$ Treatments were CTRL $=$ basal diet with no supplementation of oil or rumen-inert fat; $\mathrm{CO}=$ basal diet + $170 \mathrm{~g}$ of canola oil; Ca-FA $=$ basal diet $+200 \mathrm{~g}$ of calcium salts of palm fatty acid (Energizer Gold, IFFCO, Johor, Malaysia); and PA = basal diet $+170 \mathrm{~g}$ of palmitic acid (Energizer RP-10, IFFCO).

${ }^{2}$ The diet contained oat silage $(47.7 \%)$, wheat bran $(19.6 \%)$, wheat straw $(13.5 \%)$, canola meal $(9.97 \%)$, ground corn $(5.84 \%)$, and sugarcane molasses $(3.29 \%)$.

\section{Milk Fat Extraction}

Thirty milliliters of raw milk was centrifuged at $17,800 \times g$ for 30 min at $4^{\circ} \mathrm{C}$ in a Beckman (Fullerton, CA) J2-MC centrifuge. The fat layer was transferred to a microtube and left at room temperature for approximately 30 min before being microcentrifuged at $19,300 \times g$ for $20 \mathrm{~min}$ at room temperature. After the second centrifugation, the top layer was removed and was stored at $-20^{\circ} \mathrm{C}$ without preservative until analyzed for FA profile (Luna et al., 2005). Fifty grams of each milk sample was taken in a flask separately and a solvent mixture of $500 \mathrm{~mL}$ of chloroform-methanol (2:1) was employed for extraction of pure lipids (Kallio et al., 2006). The process was revised with the same solvent mixture $(2 \times 250 \mathrm{~mL})$ for maximum extraction. The oil was dried over anhydrous sodium sulfate and distilled

Table 2. Fatty acid (FA) profile of different fat sources ${ }^{1}$

\begin{tabular}{lccc}
\hline Item & CO & Ca-FA & PA \\
\hline Ether extract (\% of DM) & 100 & 82.5 & 95.0 \\
Total FA (\% of DM) & 88.0 & 82.5 & 95.0 \\
Glycerol (\% of DM) & 9.68 & & \\
Pigment (\% of DM) & 2.32 & & \\
\% of total FA & & & \\
C12:0 & 0.10 & 0.20 & 2.30 \\
C14:0 & 0.10 & 1.20 & 4.20 \\
C16:0 & 5.90 & 47.0 & 86.6 \\
C16:1 & 0.60 & & \\
C18:0 & 1.90 & 5.00 & 2.80 \\
C18:1 & 53.7 & 38.0 & 4.10 \\
C18:2 & 22.4 & 8.00 & \\
C18:3 & 9.80 & & \\
Others & 5.50 & 0.60 & \\
\hline
\end{tabular}

${ }^{1}$ Sources were $\mathrm{CO}=$ basal diet $+170 \mathrm{~g}$ of canola oil; $\mathrm{Ca}-\mathrm{FA}=$ basal diet $+200 \mathrm{~g}$ of calcium salts of palm fatty acid (Energizer Gold, IFFCO, Johor, Malaysia); and PA $=$ basal diet $+170 \mathrm{~g}$ of palmitic acid (Energizer RP-10, IFFCO). by rotary thin film evaporator under vacuum to get lipids before treatment with a mixture of chloroform: methanol: $0.9 \%$ sodium chloride solution $(3: 48: 47 \mathrm{vol} /$ vol) to remove impurities by a separator funnel (Kallio et al., 2006).

\section{Derivatization of Fat and GC Analysis}

The extracted lipids were esterified with Boron Trifloride-Methanol Complex (Merck-Schuchardt, Hohenbrunn, Germany) by following the official method and the FAME were analyzed on GC (AOCS, 2009, 2017a). The GC Shimadzu GC-14A and data processor C-R-4A (Shimadzu Corp., Kyoto, Japan) was used for the identification of methyl esters by standard method Ce 1a-13 (AOCS, 2017b) using a polar column (dimensions: $60 \mathrm{~m}, 0.25 \mathrm{~mm}$ i.d.). The hydrogen flame ionization detector was used with the requisite temperature of detector and injector at 250 and $230^{\circ} \mathrm{C}$, respectively. It was programmed to increase the temperature from 160 to $210^{\circ} \mathrm{C}$ at the rate of $2^{\circ} \mathrm{C} / \mathrm{min}$. The FAME were identified by the comparison of their corresponding retention times with standard methyl esters (Supelco, Bellefonte, PA) under same conditions.

\section{Statistical Analysis}

Data were analyzed using the MIXED procedure of SAS University Edition (SAS Institute Inc., Cary, NC), with main effects of period and treatments, whereas buffaloes were designated as random effect in the model. The following mathematical model was used for the analysis:

$$
\mathrm{Y}_{\mathrm{ijk}}=\mu+\text { Buff }_{\mathrm{i}}+\text { Per }_{\mathrm{j}}+\text { Treat }_{\mathrm{k}}+\varepsilon_{\mathrm{ijk}}
$$


where $\mathrm{Y}$ is the response variable, $\mu$ is the overall mean, $\varepsilon$ is the random error, Buff $f_{\mathrm{i}}$ represents the random effect of buffalo, Per $_{\mathrm{j}}$ represents the 21-d period, and Treat ${ }_{\mathrm{k}}$ represents the treatment diets of experiment. Three preplanned orthogonal contrasts were performed: (1) contrast A, CTRL vs. CO, Ca-FA, and PA to compare the effects of feeding oil and rumen-inert fats; (2) contrast B, CO vs. Ca-FA and PA to compare the feeding of oil versus rumen-inert fats; and (3) contrast $\mathrm{C}$, Ca-FA versus PA to compare the sources of rumeninert fats. Standard errors of the mean are reported and treatment differences were considered significant if $P \leq$ 0.05 and as a trend for $0.05<P \leq 0.10$.

\section{RESULTS}

\section{DM and FA Intakes}

The DMI and FA intakes are presented in Table 3. The CO, Ca-FA, and PA treatments had no effect on DMI compared with the CTRL (contrast A; $P=0.80$ ); however, the $\mathrm{CO}$ treatment decreased the DMI by $4.43 \%$ compared with Ca-FA and PA treatments (contrast $\mathrm{B} ; P=0.04)$. As expected, the $\mathrm{CO}, \mathrm{Ca}-\mathrm{FA}$, and $\mathrm{PA}$ treatments increased the intakes of $\mathrm{C} 12: 0, \mathrm{C} 14: 0$, 16-C, 18-C, and total FA (contrast A; $P \leq 0.01$ ) compared with the CTRL. The Ca-FA and PA treatments increased the intake of $\mathrm{C} 16: 0$ by $167 \%$ (contrast B; $P$ $<0.01)$ compared with the CO treatment. Contrary to this, the CO treatment increased the intakes of C18:1, C18:2, and $\mathrm{C} 18: 3$ by $57.7,15.9$, and $15.7 \%$, respectively (contrast $\mathrm{B} ; P<0.01$ ), compared with the $\mathrm{Ca}-\mathrm{FA}$ and $\mathrm{PA}$ treatments. The PA treatment increased the intake of C16:0 by $45.0 \%$ compared with the Ca-FA treatment (contrast $\mathrm{C} ; P<0.01$ ).

\section{Milk Yield and Milk Composition}

Milk yield and milk composition results are presented in Table 4. The actual milk yield and 3.5\% FCM yield were increased by $7.8 \%$ (contrast $\mathrm{A} ; P=0.02$ ) and $12.2 \%(P<0.01)$, respectively, in the CO, Ca-FA, and PA treatment compared with the CTRL, whereas, milk composition remained unaffected $(P>0.10)$. Milk yield was similar between the $\mathrm{CO}$ versus $\mathrm{Ca}-\mathrm{FA}$ and $\mathrm{PA}$ treatments (contrast $\mathrm{B} ; P=0.70$ ); however, Ca-FA and $\mathrm{PA}$ treatment tended to increase the $3.5 \% \mathrm{FCM}$ yield by $6.25 \%(P=0.10)$ and increased milk fat content by $7.51 \%(P=0.04)$ compared with the $\mathrm{CO}$ treatment. The Ca-FA treatment had no effect on DMI, milk yield, and milk composition compared with the PA treatment (contrast $\mathrm{C} ; P>0.10$ ).

\section{Milk FA Concentrations}

Results of milk FA concentrations of buffaloes fed treatment diets are presented in Table 5 . The CO, CaFA, and PA treatments tended to increase the concentrations of $\mathrm{C} 8: 0$ by $7.99 \%$ (contrast $\mathrm{A} ; P=0.08$ ) and C16:0 by $4.63 \%(P=0.09)$, whereas concentrations of C6:0, C10:0, C12:0, C14:0, C14:1, C16:1, C18:0, C18:1, and $\mathrm{C} 18: 2$ remained unaffected $(P>0.10)$ compared with the CTRL. The CO, Ca-FA, and PA had no effect on concentrations of SFA, MUFA, PUFA, UFA, SCFA, MCFA, and LCFA compared with the CTRL diet ( $P$ $>0.10)$. The Ca-FA and PA treatments increased the concentration of $\mathrm{C} 16: 0$ by $25.8 \%$ (contrast $\mathrm{B} ; \mathrm{P}<0.01$ ) compared with the CO treatment. The Ca-FA and PA treatments increased the concentration of MCFA by $18.0 \%$ (contrast B; $P<0.01$ ) compared with $\mathrm{CO}$. The $\mathrm{CO}$ treatment decreased the concentrations of $\mathrm{C} 14: 1$ by

Table 3. Dry matter and fatty acid (FA) intake $(\mathrm{g} / \mathrm{d})$ in different treatments

\begin{tabular}{|c|c|c|c|c|c|c|c|c|}
\hline Item & \multicolumn{4}{|c|}{ Treatment $^{1}$} & SEM & \multicolumn{3}{|c|}{$P$-value ${ }^{2}$} \\
\hline $\begin{array}{l}\text { DMI }(\mathrm{kg} / \mathrm{d}) \\
\text { FA intake }(\mathrm{g} / \mathrm{d})\end{array}$ & 15.6 & 15.1 & 15.9 & 15.7 & 0.25 & 0.80 & 0.04 & 0.59 \\
\hline C12:0 & 8.56 & 8.35 & 8.95 & 12.0 & 0.15 & $<0.01$ & $<0.01$ & $<0.01$ \\
\hline C14:0 & 1.68 & 1.77 & 3.63 & 8.22 & 0.072 & $<0.01$ & $<0.01$ & $<0.01$ \\
\hline C16:0 & 52.4 & 59.1 & 129 & 187 & 1.9 & $<0.01$ & $<0.01$ & $<0.01$ \\
\hline C18:1 & 44.2 & 122 & 105 & 49.7 & 1.57 & $<0.01$ & $<0.01$ & $<0.01$ \\
\hline $\mathrm{C} 18: 2$ & 129 & 157 & 144 & 127 & 2.3 & $<0.01$ & $<0.01$ & $<0.01$ \\
\hline C18:3 & 74.6 & 86.0 & 75.2 & 73.5 & 1.26 & 0.01 & $<0.01$ & 0.33 \\
\hline Other & 7.48 & 15.5 & 8.64 & 7.36 & 0.176 & $<0.01$ & $<0.01$ & $<0.01$ \\
\hline Total FA & 326 & 460 & 489 & 478 & 7.4 & $<0.01$ & 0.01 & 0.26 \\
\hline
\end{tabular}

${ }^{1}$ Treatments were CTRL $=$ basal diet with no supplementation of oil or rumen-inert fat; $\mathrm{CO}=$ basal diet $+170 \mathrm{~g}$ of canola oil; Ca-FA $=$ basal diet $+200 \mathrm{~g}$ of calcium salts of palm fatty acid (Energizer Gold, IFFCO, Johor, Malaysia); and PA = basal diet $+170 \mathrm{~g}$ of palmitic acid (Energizer RP-10, IFFCO).

${ }^{2} \mathrm{~A}=\mathrm{CTRL}$ vs. CO, Ca-FA, and PA. B = CO vs. Ca-FA and PA. C = Ca-FA vs. PA. 
Table 4. Milk yield and milk composition

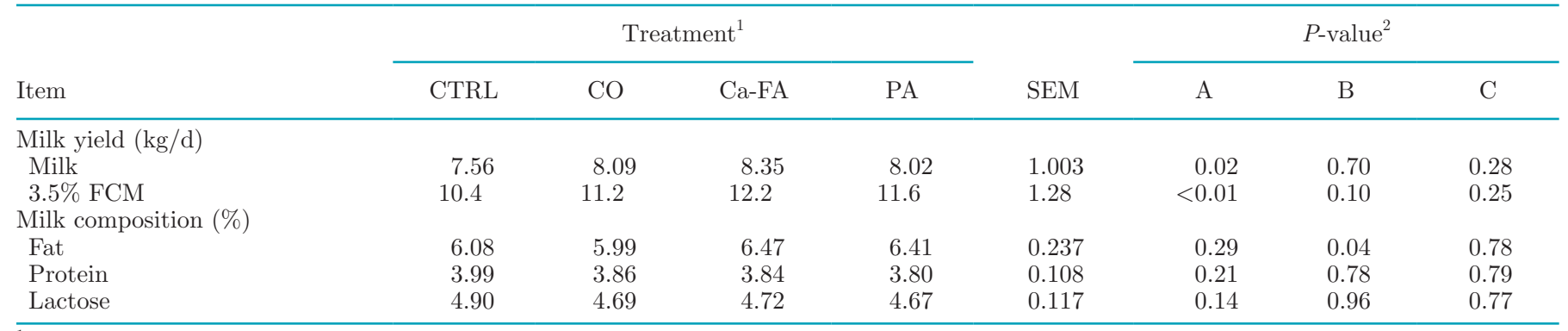

${ }^{1}$ Treatments were CTRL $=$ basal diet with no supplementation of oil or rumen-inert fat; $\mathrm{CO}=$ basal diet $+170 \mathrm{~g}$ of canola oil; Ca-FA $=$ basal diet $+200 \mathrm{~g}$ of calcium salts of palm fatty acid (Energizer Gold, IFFCO, Johor, Malaysia); and PA = basal diet $+170 \mathrm{~g}$ of palmitic acid (Energizer RP-10, IFFCO).

${ }^{2} \mathrm{~A}=\mathrm{CTRL}$ vs. CO, Ca-FA, and PA; $\mathrm{B}=\mathrm{CO}$ vs. Ca-FA and PA; $\mathrm{C}=\mathrm{Ca}-\mathrm{FA}$ vs. PA.

$13.8 \%$ (contrast $\mathrm{B} ; P=0.01$ ) and increased the concentrations of $\mathrm{C} 18: 0, \mathrm{C} 18: 1$, and $\mathrm{C} 18: 2$ by $37.2(P=0.02)$, $28.1(P<0.01)$, and $49.0 \%(P<0.01)$, respectively, compared with the Ca-FA and PA treatments. The CO treatment increased the concentrations of MUFA by $17.8 \%$ (contrast $\mathrm{B} ; P=0.02)$, PUFA by $49.1 \%(P<$ $0.01)$, UFA by $19.8 \%(P=0.01)$, and LCFA by $32.8 \%(P$ $=0.01)$ compared with the Ca-FA and PA treatments. The CO treatment had no effect on concentrations of C6:0, C8:0, C10:0, C12:0, C14:0, C16:1, SFA, and
SCFA compared with the Ca-FA and PA treatments (contrast $\mathrm{B} ; P>0.10$ ). The PA treatment increased the concentrations of $\mathrm{C} 8: 0, \mathrm{C} 14: 1$, and $\mathrm{C} 16: 1$ by 11.9 (contrast $\mathrm{C} ; P=0.02), 22.4(P<0.01)$, and $32.1 \%(P$ $=0.05)$, respectively, whereas it tended to decrease the concentration of $\mathrm{C} 18: 2$ or PUFA by $15.2 \%(P=0.07)$ relative to the Ca-FA. The PA treatment had no effect on concentrations of C6:0, C10:0, C12:0, C14:0, C16:0, C18:0, C18:1, SFA, MUFA, UFA, SCFA, MCFA, and LCFA (contrast C; $P>0.10$ ) compared with Ca-FA.

Table 5. Milk fatty acid (FA) concentrations

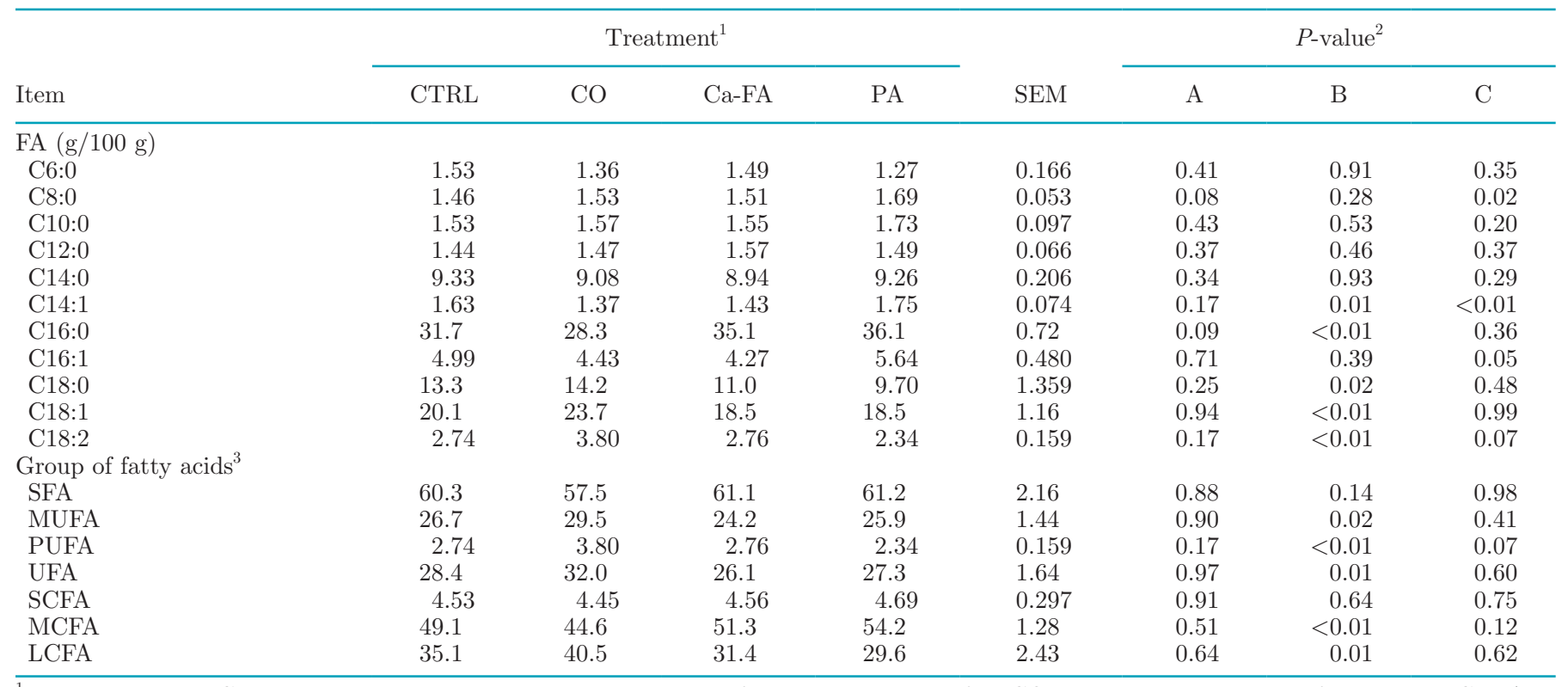

${ }^{1}$ Treatments were $\mathrm{CTRL}=$ basal diet with no supplementation of oil or rumen-inert fat; $\mathrm{CO}=$ basal diet $+170 \mathrm{~g}$ of canola oil; Ca-FA $=$ basal diet $+200 \mathrm{~g}$ of calcium salts of palm fatty acid (Energizer Gold, IFFCO, Johor, Malaysia); and PA = basal diet $+170 \mathrm{~g}$ of palmitic acid (Energizer RP-10, IFFCO).

${ }^{2} \mathrm{~A}=\mathrm{CTRL}$ vs. $\mathrm{CO}$, Ca-FA, and PA; $\mathrm{B}=\mathrm{CO}$ vs. Ca-FA and PA; C $=$ Ca-FA vs. PA.

${ }^{3} \mathrm{SCFA}=$ short-chain fatty acids, including C6:0, C8:0, and C10:0; MCFA = medium-chain fatty acids, including C12:0, C14:0, C14:1, C16:0, and C16:1; LCFA = long-chain fatty acids, including C18:0, C18:1, and C18:2. 
Table 6. Milk fatty acid (FA) yields

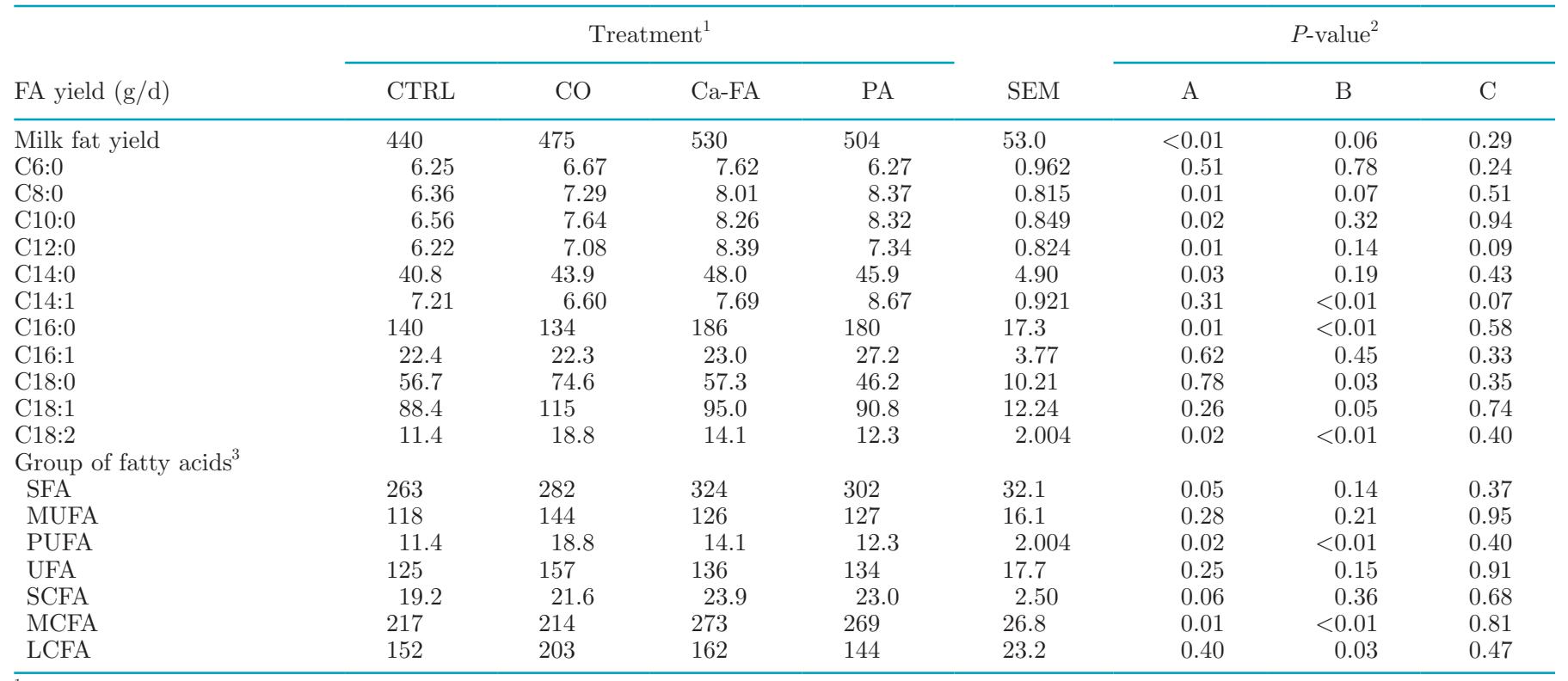

${ }^{1}$ Treatments were CTRL $=$ basal diet with no supplementation of oil or rumen-inert fat; $\mathrm{CO}=$ basal diet $+170 \mathrm{~g}$ of canola oil; Ca-FA $=$ basal diet $+200 \mathrm{~g}$ of calcium salts of palm fatty acid (Energizer Gold, IFFCO, Johor, Malaysia); and PA = basal diet $+170 \mathrm{~g}$ of palmitic acid (Energizer RP-10, IFFCO).

${ }^{2} \mathrm{~A}=\mathrm{CTRL}$ vs. $\mathrm{CO}$, Ca-FA, and $\mathrm{PA} ; \mathrm{B}=\mathrm{CO}$ vs. Ca-FA and $\mathrm{PA} ; \mathrm{C}=\mathrm{Ca}-\mathrm{FA}$ vs. $\mathrm{PA}$.

${ }^{3} \mathrm{SCFA}=$ short-chain fatty acids, including C6:0, C8:0, and C10:0; MCFA = medium-chain fatty acids, including C12:0, C14:0, C14:1, C16:0, and C16:1; LCFA = long-chain fatty acids, including C18:0, C18:1, and C18:2.

\section{Milk Fat and FA Yields}

Milk fat and milk FA yields are presented in Table 6. The CO, Ca-FA, and PA treatments increased milk fat yield by $14.3 \%$ compared with the CTRL (contrast A; $P<0.01$ ), and the Ca-FA and PA treatment tended to increase the milk fat yield by $8.84 \%$ (contrast B; $P$ $=0.06$ ) compared with the $\mathrm{CO}$ treatment without any difference observed in the Ca-FA versus PA (contrast $\mathrm{C} ; P=0.29)$. The $\mathrm{CO}, \mathrm{Ca}-\mathrm{FA}$, and PA treatments increased the yields of C8:0, C10:0, C12:0, C14:0, C16:0, and $\mathrm{C} 18: 2$ by $24.1 \%$ (contrast A; $P=0.01), 23.1 \%(P$ $=0.02), 22.2 \%(P=0.01), 12.6 \%(P=0.03), 19.1 \%(P$ $=0.01)$, and $32.2 \%(P=0.02)$, respectively, compared with the CTRL. Similarly, the CO, Ca-FA, and PA treatments also increased the yields of SFA and MCFA by $15.1 \%$ (contrast $\mathrm{A} ; P=0.05)$ and $16.1 \%(P=0.01)$ and tended to increase the yield of SCFA by $18.9 \%$ $(P=0.06)$ compared with the CTRL. The yields of C6:0, C14:1, C16:1, C18:0, C18:1, MUFA, UFA, and LCFA were not affected by the CO, Ca-FA, and PA treatments compared with the CTRL (contrast A; $P$ $>0.10)$. The Ca-FA and PA treatments increased the yield of $\mathrm{C} 16: 0$ by $36.6 \%$ (contrast $\mathrm{B} ; P<0.01$ ) and yield of MCFA by $26.6 \%(P<0.01)$ compared with $\mathrm{CO}$. The CO treatment decreased the yields of C14:1 by $19.3 \%$ (contrast $\mathrm{B} ; P<0.01$ ) and tended to decrease the yield of $\mathrm{C} 8: 0$ by $10.1 \%(P=0.07)$, whereas the yield of C18:0, C18:1, and C18:2 were increased by $44.2 \%(P=0.03), 23.8 \%(P=0.05)$, and $42.4 \%(P<$ $0.01)$, respectively, compared with Ca-FA and PA. The CO treatment increased the yields of PUFA by $42.4 \%$ (contrast B; $P<0.01)$ and LCFA by $32.7 \%(P=0.03)$ compared with the Ca-FA and PA. The yields of C6:0, C10:0, C12:0, C14:0, C16:1, SFA, MUFA, UFA, and SCFA were not different between CO versus Ca-FA and PA (contrast B; $P>0.10$ ).

The PA treatment tended to decrease the yield of C12:0 by $12.5 \%$ (contrast C; $P=0.09$ ), whereas it tended to increase the yield of $\mathrm{C} 14: 1$ by $12.7 \%(P=$ $0.07)$ compared with the Ca-FA. The Ca-FA versus PA treatments had no effect on yields of C6:0, C8:0, C10:0, C14:0, C16:0, C16:1, C18:0, C18:1, C18:2, SFA, MUFA, PUFA, UFA, SCFA, MCFA, LCFA, and milk fat yield (contrast $\mathrm{C} ; P>0.10$ ).

\section{Plasma Metabolites}

Response of plasma metabolites is presented in Table 7. The CO, Ca-FA, and PA treatments increased the concentration of plasma glucose by $8.1 \%$ (contrast A; $P=0.05)$, whereas PUN and triglyceride concentra- 


\begin{tabular}{|c|c|c|c|c|c|c|c|c|}
\hline Item & \multicolumn{4}{|c|}{ Treatment $^{1}$} & SEM & \multicolumn{3}{|c|}{$P$-value ${ }^{2}$} \\
\hline Glucose (mg/dL) & 71.8 & 79.8 & 79.4 & 73.6 & 3.12 & 0.05 & 0.33 & 0.16 \\
\hline Triglyceride $(\mathrm{mg} / \mathrm{dL})$ & 189 & 186 & 212 & 200 & 13.3 & 0.40 & 0.15 & 0.44 \\
\hline
\end{tabular}

${ }^{1}$ Treatments were CTRL $=$ basal diet with no supplementation of oil or rumen-inert fat; CO $=$ basal diet $+170 \mathrm{~g}$ of canola oil; Ca-FA $=$ basal diet $+200 \mathrm{~g}$ of calcium salts of palm fatty acid (Energizer Gold, IFFCO, Johor, Malaysia); and PA = basal diet $+170 \mathrm{~g}$ of palmitic acid (Energizer RP-10, IFFCO).

${ }^{2} \mathrm{~A}=\mathrm{CTRL}$ vs. $\mathrm{CO}, \mathrm{Ca}-\mathrm{FA}$, and $\mathrm{PA} ; \mathrm{B}=\mathrm{CO}$ vs. Ca-FA and $\mathrm{PA} ; \mathrm{C}=\mathrm{Ca}-\mathrm{FA}$ vs. PA.

tions were not affected compared with the CTRL $(P$ $>0.10$ ). Similarly, CO treatment had no effect on concentrations of plasma glucose, PUN, and triglyceride compared with Ca-FA and PA (contrast B; $P>0.10$ ). We found no effect of Ca-FA versus PA treatments on plasma glucose, PUN, and triglyceride concentrations (contrast $\mathrm{C} ; P>0.10$ ).

\section{DISCUSSION}

Our objective was to investigate the effects of feeding rumen-inert fats on milk production and milk composition in lactating dairy buffaloes compared with a diet without any supplemental fat or oil source (CTRL) as well as with a diet containing oil (CO). Canola oil was high in UFA contents (mainly C18:1 and C18:2) and was potentially exposed to rumen biohydrogenation (DePeters et al., 2001). The PA supplement was concentrated in C16:0, designed to minimize negative effects on rumen fermentation. In contrast, the Ca-FA supplement was a source of both SFA (mainly C16:0) and UFA (mainly C18:1) complexes with a calcium ion to slow down rumen availability of UFA for microbial biohydrogenation.

\section{Canola Oil Supplementation Decreased the DMI Compared with the Rumen-Inert Fats}

In the current study, we observed a decrease in the DMI due to the CO treatment compared with the feeding of rumen-inert fats (Ca-FA and PA). This result was in agreement with the studies conducted on dairy cows, where feeding the UFA decreased the DMI compared with the SFA (Jenkins and Jenny, 1989; Harvatine and Allen, 2006; Rabiee et al., 2012). However, no difference was observed between the Ca-FA versus PA treatments, in agreement with the studies conducted on dairy cows (Rico et al., 2014a). It is possible that the higher supply of UFA in the CO treatment exceeds the microbial capacity to convert them into the SFA, leading to an impede ruminal fermentation (NRC, 2001; Rabiee et al., 2012).

\section{Milk Yield Increased Similarly with Oil and Rumen-Inert Fats}

As expected, the additional intake of energy provided by the $\mathrm{CO}, \mathrm{Ca}-\mathrm{FA}$, and $\mathrm{PA}$ treatments increased the milk yield by $7.8 \%$ compared with the CTRL, in agreement with the studies conducted on lactating buffaloes (Polidori et al., 1997) and cows (de Souza et al., 2017; Batistel et al., 2017). Fat supplementation may spare glucose that could be used for the lactose synthesis (Palmquist and Jenkins, 1980). We observed an increase in the plasma glucose by the CO, Ca-FA, and PA treatments compared with the CTRL. Moreover, a large proportion of the absorbed LCFA could be oxidized by the extrahepatic tissues, thereby decreasing its export in milk and sparing other fuels (FA) for milk synthesis (Piantoni et al., 2015). Interestingly, in the current study, milk yield in the CO treatment was similar to Ca-FA and PA despite a decrease in the DMI. Feeding of oil has been shown to decrease the DMI more rapidly compared with milk yield, as shown by Rico and Harvatine (2013). In their study, feeding of soybean oil to lactating dairy cows in a 21-d period decreased the DMI between d 6 to 21, whereas the average milk yield remained unaffected due to treatment and was only decreased at d 20 (Rico and Harvatine, 2013). It is also possible that the slight decrease in protein intake ( $82 \mathrm{~g})$ in the $\mathrm{CO}$ treatment compared with Ca-FA and PA was compensated through recycling of nitrogen, as proposed by Reynolds and Kristensen (2008). Nevertheless, the 3.5\% FCM showed a tendency toward increase in Ca-FA and PA compared with the $\mathrm{CO}$ treatment in our study.

\section{Milk Fat Content Increased by Feeding of Rumen-Inert Fat}

Milk fat concentration was increased by $7.5 \%$ with the addition of Ca-FA and PA compared with the $\mathrm{CO}$ treatment. This increase was mainly related to the increase in the concentration of $\mathrm{C} 16: 0$ by $25.6 \%$, as observed in previous studies (Jenkins and Jenny, 1992; 
Baumann et al., 2016). On the other hand, the concentrations of C18:0, C18:1, and C18:2 were higher in the $\mathrm{CO}$ treatment, in agreement with the literature (Jenkins and Jenny, 1992; DePeters et al., 2001; Baumann et al., 2016). Higher C18:1 concentration in milk has been associated with higher ruminal biohydrogenation of canola oil and, as a consequence, decreased the milk fat percentage (DePeters et al., 2001), as observed in the CO treatment of our study. The effect of feeding calcium soaps of FA in lactating buffalo was investigated by Polidori et al. (1997), but despite feeding 300 $\mathrm{g} / \mathrm{d}$ of calcium soaps of FA ( $2 \%$ of the DM), they found no effect on milk fat content. The response of feeding fats is related to the stage of lactation (Chilliard, 1993). The buffaloes in the study of Polidori et al. (1997) were in mid to late lactation, whereas in our study they were in mid lactation, which could possibly explain the differences in milk fat content response between the 2 studies. Nevertheless, feeding unsaturated plant oils, such as canola oil, led to the production of trans FA as an intermediate of ruminal biohydrogenation, inhibiting de novo FA synthesis (Baumgard et al., 2000; Bauman and Griinari, 2001; Shingfield and Griinari, 2007). However, feeding of $\mathrm{CO}$ did not create any milk fat depression in our study, contrary to the studies where they fed canola oil (DePeters et al., 2001) or canola seed (Chichlowski et al., 2005). This could be due to the low level of canola oil feeding in the current study (i.e., $1.1 \%$ of the DM) compared with $1.6 \%$ in the study by DePeters et al. (2001).

\section{Feeding Rumen-Inert Fats Increased Milk C16:0 Content and Yield}

As expected, in the current experiment, concentration and yield of C16:0 were increased in Ca-FA and PA treatments by 26 and $37 \%$, respectively, compared with $\mathrm{CO}$ treatment, in agreement with the literature on dairy cows (Jenkins and Jenny, 1992; Baumann et al., 2016). The concentration of C16:0 in milk has been reported to vary from 5 to $48 \%$ by feeding of rumen-inert fats (Mosley et al., 2007; Batistel et al., 2017). Similarly, the C16:0 yield in milk was reported to vary from 14.3 to $63 \%$ by feeding rumen-inert fats (Mosley et al., 2007; Rico et al., 2014b; Batistel et al., 2017). The mammary gland appears to prefer the dietary C16:0 for incorporation into milk fat over other FA (Loften et al., 2014), and additional C16:0 consumed is partitioned to milk fat directly (Warntjes et al., 2008). Kinsella and Gross (1973) reported that $\mathrm{C} 16: 0$ was the main FA used for initiation of glycerolipid synthesis by acylation at the sn-1 position. In addition, Hansen and Knudsen (1987) reported that C16:0 stimulated de novo FA synthesis and incorporation into the milk triglycerides. The de novo synthesis of C8:0, C10:0, C12:0, and C14:0 in our study (as shown by their yields) could also be related to the stimulatory effect of C16:0, as proposed by Rico et al. (2014a), leading to an increase in milk fat yield in the current experiment. Increased de novo synthesis of C8:0, C10:0, C12:0, and C14:0 in CTRL versus CO, $\mathrm{Ca}-\mathrm{FA}$, and PA might reflect the increase in the extent of ruminal biohydrogenation, leading to increased milk fat yield, as proposed by Mosley et al. (2007).

\section{Similar Milk Fat Yield in the Ca-FA and PA Treatments}

We found no difference in milk fat yield, mainly due to the similar milk C16:0 in Ca-FA versus PA treatments. This could be due to the decrease in de novo synthesis of C16:0 in PA treatment. The de novo synthesis of C16:0 followed the law of diminishing returns, as it decreased with the increase in the dietary C16:0 concentration, in agreement with the literature in dairy cattle (Grummer, 1991; Mosley et al., 2007). In our study, the FA intake-to-milk output ratios were 2.67, $2.28,1.45$, and 0.96 in CTRL, CO, Ca-FA, and PA treatments, respectively. Mosley et al. (2007) showed a decrease in FA intake-to-milk output ratio from 2.66 to 0.53 in dairy cows where the targeted C16:0 intake was increased from 112 to $1140 \mathrm{~g} / \mathrm{d}$. This decrease in the transfer of C16:0 from feed to milk with the increase in supply could be related to its oxidation as a metabolic fuel rather than export as milk triglycerides, as suggested by Piantoni et al. (2013).

\section{A Higher Concentration of Milk C18:0 in the Oil Treatment}

The canola oil treatment increased the milk LCFA (C18:0, C18:1, and C18:2) content compared with CaFA and PA treatments, similar to the observations by DePeters et al. (2001). This increase in LCFA tended to decrease the de novo synthesis of C8:0 in our study, in agreement with the findings of Santillo et al. (2016), where feeding of flaxseed to the lactating buffaloes increased the concentration of LCFA and decreased C8:0 and C10:0. Furthermore, the ratio between LCFA to MCFA was higher in CO (0.95) compared with Ca-FA and PA (0.56) treatments, indicating the changes in carbon number for triglyceride structure, as reported by DePeters et al. (2001). Supplemental C18:0 was preferentially incorporated into the milk fat triglyceride at the expense of $\mathrm{C} 16: 0$, as has been previously reported (DePeters et al., 2001), effectively lowering its content and increasing C18:0. 


\section{CONCLUSIONS}

In the current study, oil and rumen-inert fats increased milk yield, milk fat yield, and altered milk FA profile compared with the control, in lactating dairy buffalo. Feeding Ca-FA and PA increased milk fat content and tended to increase the milk fat yield compared with oil. We observed no difference in lactation performance of buffaloes with the feeding of Ca-FA and PA under the current experimental conditions. The findings of our study showed that feeding of rumen-inert fat is a useful strategy to increase the $3.5 \%$ FCM yield due to higher milk fat content in lactating buffalo compared with oil.

\section{ACKNOWLEDGMENTS}

We acknowledge the support of dairy farm staff of University of Veterinary \& Animal Sciences, Lahore, Pakistan, for their assistance in this research work. The authors thank the laboratory staff of University of Veterinary \& Animal Sciences, Lahore, Pakistan, for providing support in proximate analysis and Muhammad Imran, Department of Biochemistry, for analysis of plasma. We also thank the staff of Pakistan Council of Scientific and Industrial Research Laboratories Complex, Lahore, Pakistan, for their help in analysis of milk samples for individual fatty acids through gas chromatography. We acknowledge the support of Ghazi Brothers Pvt. Ltd. (Lahore, Pakistan) for providing the rumen-inert fats used in this research at low price.

\section{REFERENCES}

AOAC International. 2005. Official Methods of Analysis. 18th ed. AOAC International, Gaithersburg, MD.

AOCS. 2009. Official Method Ce 1j-07. Determination of cis-, trans-, saturated, monounsaturated, and polyunsaturated fatty acids in extracted fats by capillary GLC. Am. Oil Chem. Soc. Press, Champaign, IL.

AOCS. 2017a. Official Method Ce 2-66. Preparation of methyl esters of fatty acids. Official Methods and Recommended Practices of the American Oil Chemists Society. 7th ed. Am. Oil. Chem. Soc., Urbana, IL.

AOCS. 2017b. Official Method Ce 1a-13. Fatty acids in edible oils and fats by capillary GLC. Official Methods and Recommended Practices of the American Oil Chemists Society. 7th ed. Am. Oil. Chem. Soc., Urbana, IL.

Batistel, F., J. de Souza, and F. A. P. Santos. 2017. Corn grain-processing method interacts with calcium salts of palm fatty acids supplementation on milk production and energy balance of earlylactation cows grazing tropical pasture. J. Dairy Sci. 100:53435357.

Bauman, D. E., and J. M. Griinari. 2001. Regulation and nutritional manipulation of milk fat: Low-fat milk syndrome. Livest. Prod. Sci. 70:15-29.

Baumann, E., P. Y. Chouinard, Y. Lebeuf, D. E. Rico, and R. Gervais. 2016. Effect of lipid supplementation on milk odd-and branchedchain fatty acids in dairy cows. J. Dairy Sci. 99:6311-6323.

Baumgard, L. H., B. A. Corl, D. A. Dwyer, A. Sæbø, and D. E. Bauman. 2000. Identification of the conjugated linoleic acid isomer that inhibits milk fat synthesis. Am. J. Physiol. Regul. Integr. Comp. Physiol. 278:R179-R184.

Chichlowski, M. W., J. Schroeder, C. Park, W. Keller, and D. Schimek. 2005. Altering the fatty acids in milk fat by including canola seed in dairy cattle diets. J. Dairy Sci. 88:3084-3094.

Chilliard, Y. 1993. Dietary fat and adipose tissue metabolism in ruminants, pigs, and rodents: A review. J. Dairy Sci. 76:3897-3931.

Chouinard, P. Y., V. Girard, and G. Brisson. 1997. Performance and profiles of milk fatty acids of cows fed full fat, heat-treated soybeans using various processing methods. J. Dairy Sci. 80:334-342.

Conte, G., A. Serra, P. Cremonesi, S. Chessa, B. Castiglioni, A. Cappucci, E. Bulleri, and M. Mele. 2016. Investigating mutual relationship among milk fatty acids by multivariate factor analysis in dairy cows. Livest. Sci. 188:124-132.

de Souza, J., F. Batistel, and F. A. P. Santos. 2017. Effect of sources of calcium salts of fatty acids on production, nutrient digestibility, energy balance, and carryover effects of early lactation grazing dairy cows. J. Dairy Sci. 100:1072-1085.

DePeters, E. J., J. German, S. Taylor, S. Essex, and H. Perez-Monti. 2001. Fatty acid and triglyceride composition of milk fat from lactating Holstein cows in response to supplemental canola oil. J. Dairy Sci. 84:929-936.

FAOSTAT. 2016. Statistical database. Food and Agriculture Organization of the United Nations, Rome, Italy. Accessed Jun. 20, 2018 http://faostat3.fao.org.

Fox, D. G., T. P. Tylutki, L. O. Tedeschi, M. E. Van Amburgh, L. E. Chase, A. N. Pell, T. R. Overton, and J. B. Russell. 2003. The Net Carbohydrate and Protein System for Evaluating Herd Nutrition and Nutrient Excretion: Model Documentation. Mimeo No. 213, Animal Science Department. Cornell University, Ithaca, NY.

Giesy, J. G., M. McGuire, B. Shafii, and T. Hanson. 2002. Effect of dose of calcium salts of conjugated linoleic acid (CLA) on percentage and fatty acid content of milk fat in midlactation Holstein cows. J. Dairy Sci. 85:2023-2029.

Grummer, R. R. 1991. Effect of feed on the composition of milk fat. J. Dairy Sci. 74:3244-3257.

Hansen, H. O., and J. Knudsen. 1987. Effect of exogenous long-chain fatty acids on individual fatty acid synthesis by dispersed ruminant mammary gland cells. J. Dairy Sci. 70:1350-1354.

Haque, M. N., H. Rulquin, A. Andrade, P. Faverdin, J. L. Peyraud, and S. Lemosquet. 2012. Milk protein synthesis in response to the provision of an "ideal" amino acid profile at 2 levels of metabolizable protein supply in dairy cows. J. Dairy Sci. 95:5876-5887.

Harvatine, K. J., and M. Allen. 2006. Effects of fatty acid supplements on feed intake, and feeding and chewing behavior of lactating dairy cows. J. Dairy Sci. 89:1104-1112.

Jenkins, T. C., and M. McGuire. 2006. Major advances in nutrition: impact on milk composition. J. Dairy Sci. 89:1302-1310.

Jenkins, T. C., and B. F. Jenny. 1989. Effect of hydrogenated fat on feed intake, nutrient digestion, and lactation performance of dairy cows. J. Dairy Sci. 72:2316-2324.

Jenkins, T. C., and B. F. Jenny. 1992. Nutrient digestion and lactation performance of dairy cows fed combinations of prilled fat and canola oil. J. Dairy Sci. 75:796-803.

Kallio, H., K. Korkiasaari, O. Sjövall, J. P. Suomela, and K. Linderborg. 2006. The regiospecific position of 18: 1 cis and trans monoenoic fatty acids in milk fat triacylglycerols. J. Am. Oil Chem. Soc. 83:407-413.

Kinsella, J. E., and M. Gross. 1973. Palmitic acid and initiation of mammary glyceride synthesis via phosphatidic acid. Biochim. Biophys. Acta 316:109-113.

Lock, A. L., C. Preseault, J. Rico, K. DeLand, and M. Allen. 2013. Feeding a C16:0 enriched fat supplement increased the yield of milk fat and improved conversion of feed to milk. J. Dairy Sci. 96:6650-6659

Loften, J. R., J. Linn, J. Drackley, T. Jenkins, C. Soderholm, and A. Kertz. 2014. Invited review: Palmitic and stearic acid metabolism in lactating dairy cows. J. Dairy Sci. 97:4661-4674.

Luna, P., M. Juárez, and M. De la Fuente. 2005. Validation of a rapid milk fat separation method to determine the fatty acid profile by gas chromatography. J. Dairy Sci. 88:3377-3381. 
Mosley, S. A., E. Mosley, B. Hatch, J. Szasz, A. Corato, N. Zacharias, D. Howes, and M. McGuire. 2007. Effect of varying levels of fatty acids from palm oil on feed intake and milk production in Holstein cows. J. Dairy Sci. 90:987-993.

NRC. 2001. Nutrient Requirements of Dairy Cattle. 7th rev. ed. Natl. Acad. Press, Washington, DC.

Palmquist, D. L., and T. Jenkins. 1980. Fat in lactation rations. J. Dairy Sci. 63:1-14. (Review).

Pantoja, J., J. Firkins, and M. Eastridge. 1996. Fatty acid digestibility and lactation performance by dairy cows fed fats varying in degree of saturation. J. Dairy Sci. 79:429-437.

Pegolo, S., G. Stocco, M. Mele, S. Schiavon, G. Bittante, and A. Cecchinato. 2017. Factors affecting variations in the detailed fatty acid profile of Mediterranean buffalo milk determined by 2-dimensional gas chromatography. J. Dairy Sci. 100:2564-2576.

Piantoni, P., A. Lock, and M. S. Allen. 2013. Palmitic acid increased yields of milk and milk fat and nutrient digestibility across production level of lactating cows. J. Dairy Sci. 96:7143-7154.

Piantoni, P., A. L. Lock, and M. S. Allen. 2015. Milk production responses to dietary stearic acid vary by production level in dairy cattle. J. Dairy Sci. 98:1938-1949.

Polidori, F., C. S. Rossi, E. Senatore, G. Savoini, and V. Dell'Orto. 1997. Effect of recombinant bovine somatotropin and calcium salts of long-chain fatty acids on milk from Italian buffalo. J. Dairy Sci. 80:2137-2142.

Rabiee, A. R., K. Breinhild, W. Scott, H. Golder, E. Block, and I. Lean. 2012. Effect of fat additions to diets of dairy cattle on milk production and components: A meta-analysis and meta-regression. J. Dairy Sci. 95:3225-3247.

Reynolds, C. K., and N. B. Kristensen. 2008. Nitrogen recycling through the gut and the nitrogen economy of ruminants: An asynchronous symbiosis. J. Anim. Sci. 86(Suppl. 14):E293-E305.

Rico, D. E., and K. J. Harvatine. 2013. Induction of and recovery from milk fat depression occurs progressively in dairy cows switched between diets that differ in fiber and oil concentration. J. Dairy Sci. 96:6621-6630.
Rico, D. E., Y. Ying, and K. J. Harvatine. 2014a. Effect of a highpalmitic acid fat supplement on milk production and apparent total-tract digestibility in high-and low-milk yield dairy cows. J. Dairy Sci. 97:3739-3751.

Rico, J. E., M. S. Allen, and A. L. Lock. 2014b. Compared with stearic acid, palmitic acid increased the yield of milk fat and improved feed efficiency across production level of cows. J. Dairy Sci. 97:1057-1066.

Santillo, A., M. Caroprese, R. O. Marino, A. Sevi, and M. Albenzio. 2016. Quality of buffalo milk as affected by dietary protein level and flaxseed supplementation. J. Dairy Sci. 99:7725-7732.

Shelke, S. K., S. S. Thakur, and S. A. Amrutkar. 2012. Effect of feeding protected fat and proteins on milk production, composition and nutrient utilization in Murrah buffaloes (Bubalus bubalis). Anim. Feed Sci. Technol. 171:98-107.

Shingfield, K. J., and J. M. Griinari. 2007. Role of biohydrogenation intermediates in milk fat depression. Eur. J. Lipid Sci. Technol. 109:799-816.

Tanaka, K. 2005. Occurrence of conjugated linoleic acid in ruminant products and its physiological functions. Anim. Sci. J. 76:291-303.

Wang, J. P., D. Bu, J. Wang, X. Huo, T. Guo, H. Wei, L. Zhou, R. Rastani, L. Baumgard, and F. Li. 2010. Effect of saturated fatty acid supplementation on production and metabolism indices in heat-stressed mid-lactation dairy cows. J. Dairy Sci. 93:4121-4127.

Warntjes, J. L., P. Robinson, E. Galo, E. DePeters, and D. Howes. 2008. Effects of feeding supplemental palmitic acid (C16: 0) on performance and milk fatty acid profile of lactating dairy cows under summer heat. Anim. Feed Sci. Technol. 140:241-257.

Welter, K. C., C. M. M. R. Martins, A. S. V. de Palma, M. M. Martins, B. R. dos Reis, B. L. U. Schmidt, and A. S. Netto. 2016 Canola oil in lactating dairy cow diets reduces milk saturated fatty acids and improves its omega-3 and oleic fatty acid content. PLoS One 11:e0151876.

Wu, Z., O. Ohajuruka, and D. Palmquist. 1991. Ruminal synthesis, biohydrogenation, and digestibility of fatty acids by dairy cows. J. Dairy Sci. 74:3025-3034 